Research paper

\title{
Influence of external shading on optimum insulation thickness of building walls in a tropical region
}

\author{
Elvis Wati ${ }^{\text {a, }}{ }^{*}$, Pierre Meukam ${ }^{\text {b }}$, Modeste K. Nematchoua ${ }^{\text {a }}$ \\ ${ }^{a}$ Environmental Energy Technologies Laboratory, University of Yaoundé I, Cameroon \\ ${ }^{\mathrm{b}}$ Laboratory of Energy, Water and Environment (L3E), National Advanced School of Engineering, Yaoundé, Cameroon
}

\section{H I G H L I G H T S}

- The effect of external shading on optimum insulation thickness is investigated.

- The investigation is carried out by using an explicit finite volume method.

- Intercepting the direct solar radiation has a great effect on peak cooling load.

- The optimum insulation thickness with respect to shade level is determined.

\section{A R T I C L E I N F O}

\section{Article history:}

Received 3 June 2015

Accepted 16 July 2015

Available online 29 July 2015

\section{Keywords:}

Shade level

Finite control volume

Optimum insulation thickness

Energy savings

Payback period

\begin{abstract}
A B S T R A C T
This study aims to optimize the thicknesses of insulation layers in external walls of continuously used building in a tropical region according to shade level. The investigation is carried out under steady periodic conditions for various wall orientations using a Simulink model constructed from $\mathrm{H}$-Tools (the library of Simulink models). Walls are assumed to be insulated using expanded polystyrene material. The shade level of the building site is assumed to be varying from 0 to $97 \%$ with an increment of $25 \%$ or $22 \%$. Yearly cooling load is calculated and used as input to an economic model for the determination of the optimum insulation thickness. It is seen that as shade level increases, optimum insulation thickness decreases at an average rate of $0.035 \mathrm{~cm}, 0.029 \mathrm{~cm}$ and $0.036 \mathrm{~cm}$ per percentage of solar radiation blocked for south, north and east/west oriented wall, respectively. Results also show that energy savings vary between $46.89 \$ \mathrm{~m}^{-2}$ and $101.29 \$ \mathrm{~m}^{-2}$ and payback periods vary between 3.56 years and 4.97 years depending on shade level and wall orientation.
\end{abstract}

(๑) 2015 Elsevier Ltd. All rights reserved.

\section{Introduction}

The increase in energy consumption worldwide of building sector, due to improvement in standard of living and deterioration of the thermal quality of recent constructions, has a significant impact on the operational cost of the building and the environment. In this regard, it is important to promote the passive techniques for reduction of energy requirement. Walls and roofs have to be designed to operate as passive systems over the lifetime of buildings, because an important part of heating and cooling requirements of the zone is due to heat transfer through the building envelope. A passive system is an assembly of natural and architectural components, such as shading, orientation, insulation and

\footnotetext{
* Corresponding author. Tel.: +237 674524932.

E-mail address: watielvice05@yahoo.fr (E. Wati).
}

thermal mass of the building which decrease the energy used for cooling and heating buildings.

The impact of external shading on energy conservation of the building was studied by many authors. The influence of the presence of plants on the outside surface heat flux was also studied experimentally by Papadakis et al. [1]. The south-west oriented wall of a building at the Agricultural University of Athens was chosen for investigations. Results presented for 4 summer days show that the radiative and the thermal loads in shaded area are much lower than in unshaded area.

In Hong Kong, the influence of adjacent shading on the energy requirement of a residential building was investigated by Chan [2]. Results show that some layout design can provide reduction in annual cooling of up to $18.3 \%$ compared to the layout design without adjacent shading effect.

The effect of shading by neighboring buildings and trees on household energy consumption in Canada was studied by 
Nikoofard et al. [3]. The study was conducted using the ESP-r simulation program. A two-storey house was chosen as the test case house. The impact of surrounding objects on the energy requirement was investigated. It was found that the cooling and heating energy requirement can be affected by $90 \%$ and $10 \%$, respectively.

The insulation of building external walls significantly reduces the heating and cooling requirements of the zone. The increase in insulation thickness decreases energy requirement and, thus, the energy cost but increases the initial cost of the structure. The determination of the thickness of insulation layer that minimize the total cost of insulation and energy consumption over the lifetime of the building is absolutely necessary for economic analyzes.

Many authors determined the optimum thickness from the yearly transmission loads estimated, by assuming the steady-state heat transfer using the degree-days or degree-hours concepts $[4,5]$. These methods present the inconvenience of not taking into consideration the effects of solar radiation and thermal mass. Yu et al. [6] used the solar-air cooling degree-days and heating degreedays concepts to determine the optimum insulation thickness in four cities in China. Solar-air cooling degree-days and heating degree-days are obtained from the difference between the solar-air temperature and indoor base temperature. Other authors determined the optimum insulation thickness from the annual transmission loads calculated under transient conditions using analytical methods $[7,8]$ or numerical methods $[9,10]$.

Numerical methods, such as finite difference methods, finite control volume methods, finite element method, transfer function method etc. [11], are often used for the calculation of heat-transfer through the building envelope. Numerous validated dynamic software used to simulate a building thermal behavior, applies the transfer function approach (e.g. TRNSYS, EnergyPlus, Xam). This method is not suitable for heavy walls having high thermal mass when using the time step of an hour [12]. Other validated software for building simulation use finite element (e.g. HAMFitPlus, TRNSYS ITT) or finite control volume approach (e.g. IDA-ICE, HTools). H-Tools which is a library of Simulink models offers the possibility to adjust each existed block for specific user demand. In this work, H-Tools components [13] are used to solve the nonlinear problem describing the heat transfer through a typical multilayer wall.

The effects of many design features on cooling and/or heating transmission loads and, thus, on optimum insulation thickness were studied by many authors. The influence of wall orientation on the optimum insulation thickness of external wall was investigated by some authors. According to results obtained by Daouas [8] and Ozel [14], optimum insulation can vary up to $1.6 \mathrm{~cm}$ and $0.5 \mathrm{~cm}$ when changing the wall orientation, respectively. The study of Yu et al. [6] in four China typical cities based both on cooling and heating transmission loads, showed that the effect of color on optimum insulation thickness is insignificant. Likewise, the study of Ozël [15] based on both cooling and heating transmission loads showed that solar absorptivity has very small effect on the optimum insulation thickness in the climatic conditions of Elazig, Turkye.

In the tropical regions, ambient temperatures and solar radiation levels are sufficiently high that, even during winter, buildings do not need energy for heating [16]. Thus, shading and/or insulation of the buildings located in these areas should be essentially beneficial. As can be seen in the literature survey, studies aiming to determine the optimum insulation thickness did not include the shade level of the building site. However, in the most Sub-Saharan African countries, the buildings using the HVAC systems are mainly located in urban areas where shading provided by surrounding buildings is often significant.
The objective of this work is to determine the optimum insulation thickness of a building exterior walls, energy savings and payback periods with respect to shade level of the building site. The study is carried out under the climatic conditions of Douala in Cameroon located in the tropical region by assuming five shade levels $(0,25,50,75$ and $97 \%$ shades $)$.

\section{Methodology}

\subsection{Mathematical formulation}

A model of composite wall used in this study is described in Fig. 1. The outside surface is exposed to ambient conditions while the inside surface is exposed to room air maintained at constant temperature. Unidirectional heat flow is assumed since the thickness of the wall is generally small according to its width and height [15]. This assumption is made in many validated software for building simulation (e.g. TRNSYS, WUFI-Plus, EnergyPlus, HamTools) [11]. Assuming perfect contact between the layers, the temperature $T(x, t)$ at $x$ coordinate point and at time $t$ verifies the following equation:

$c_{j} \rho_{j} \frac{\partial T(x, t)}{\partial t}=\lambda_{j} \frac{\partial^{2} T(x, t)}{\partial x^{2}}$

where the subscript $\mathrm{j}$ represents the jth layer of the composite wall and $\lambda_{j}, c_{j}$ and $\rho_{j}$ are the thermal conductivity, the specific heat and the density of the jth layer, respectively.

To solve Eq. (1), an initial condition and two boundary conditions need to be specified. At $t=0$, it is assumed that all points of the wall are at the same temperature which is equal to the room air temperature. The boundary condition at the inside surface is shown in Eq. (2).

$-\lambda_{M}\left(\frac{\partial T}{\partial x}\right)_{x=L}=h_{i}\left(T_{x=L}-T_{i}\right)$

where $\lambda_{M}$ is the thermal conductivity of the inner layer of the composite wall, $h_{i}$ is the combined convection and radiation heat transfer coefficient at the inside surface, $L$ is the thickness of the composite wall and $T_{i}$ is the indoor air temperature.

At the outside surface, the boundary condition is given by:

$-\lambda_{1}\left(\frac{\partial T}{\partial x}\right)_{x_{1}=0}=h_{0}\left(T_{s a}-T_{x=0}\right)$

where $\lambda_{1}$ is the thermal conductivity of the outer layer of composite wall, $h_{o}$ is the combined convection and radiation heat transfer coefficient at the outside wall and $T_{s a}$ is the solar-air temperature.

$T_{s a}=T_{o}+\frac{\alpha}{h_{o}} I_{t}$

where $T_{0}$ is the ambient air temperature, $\alpha$ is the solar absorptivity and $I_{t}$ is the total solar radiation incident on the tilted surface which can be expressed as:

$I_{t}=\left(\frac{\cos \theta}{\cos \theta_{z}} I_{b}+\frac{1+\cos \beta}{2} I_{d}+\frac{1-\cos \beta}{2} I \cdot \rho_{r}\right)\left(1-\frac{s d}{100}\right)$

where $I_{b}, I_{d}$ and $I$ are direct, diffuse and global solar radiations on the horizontal plane respectively; $\rho_{r}$ is the ground reflectivity taken as 0.2 in this study; $\theta$ is the incident angle; $\theta_{z}$ is the zenith angle; $\beta$ is the tilted surface angle with respect to the horizontal and $s d$, expressed in percentage, defines the shade level. $s d=0$ ( $0 \%$ shade) 


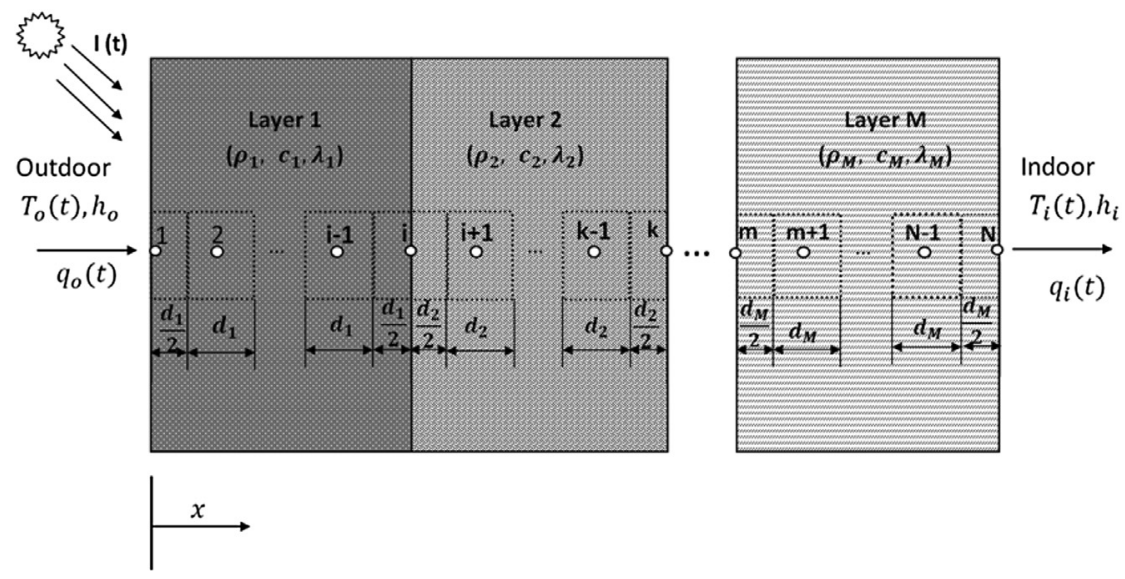

Fig. 1. Composite wall of M layers with boundary conditions and grid arrangement.

means the sunlight is allowed to fall on the outside surface of the wall without any barrier.

$$
\begin{aligned}
\cos \theta= & \sin \delta \sin \phi \cos \beta-\sin \delta \cos \phi \sin \beta \cos \gamma \\
& +\cos \delta \cos \phi \cos \beta \cos \omega+\cos \delta \sin \phi \sin \beta \cos \gamma \cos \omega \\
& +\cos \delta \sin \beta \sin \gamma \sin \omega
\end{aligned}
$$

$\cos \theta_{z}=\cos \phi \cos \delta \cos \omega+\sin \phi \sin \delta$

where $\delta, \phi$ and $\omega$ are the declination, latitude and hour angle, respectively and $\gamma$ is the azimuth angle of the surface. The values of $\gamma$ are $-90^{\circ}, 0^{\circ}, 90^{\circ}$ and $180^{\circ}$ for wall facing east, south, west and north, respectively.

\subsection{Calculation method}

To solve the above non-linear problem, a Simulink model is constructed from $\mathrm{H}$-Tools which is a library of models developed by Chalmers University of Technology (Sweden) in partnership with Technical University of Denmark and it is publicly available for free downloading. In the wall model used in this work, each sandwich layer consists of five "material" nodes blocks while external or internal layer consists of three "material" nodes blocks and a "surface material" node block. The validation of the above used blocks was done by comparing its results with those from Match (commercial and "reliable" HM program) [17]. In this study, the following Simulink parameters are used: solver: ode23tb (stiff/TR-BDF2); maximum time step: $3600 \mathrm{~s}$.

It is assumed in this work that, during each month, the climatic variables on the outside surface are periodic. Thus, the daily cycle of the solar-air temperature, representing the monthly average, is repeated on consecutive days during a month.

The numerical solution of the above non-linear problem shows the instantaneous temperature at the inside surface, which is used to estimate the instantaneous heat gain/loss by the zone as:

$q_{i}=h_{i}\left(T_{X=L}-T_{i}\right)$

Daily cooling and heating transmission loads are obtained by integrating the positive and negative values of $q_{i}$, respectively, over a period of $24 \mathrm{~h}$ when the steady periodic condition is reached. Yearly cooling and heating transmission loads are obtained by adding daily cooling and heating loads, respectively.

\subsection{Hourly climatic variables estimation}

The climatic variables required by the weather block of the Simulink model to carry out simulations in this study are hourly data of air temperature, global and diffuse radiation on horizontal surface and normal direct radiation. In the absence of hourly measured climatic variables for Douala, some techniques were employed to interpolate the available climatic data (see Appendix for details).

\subsection{Description of building walls}

The common materials used for the construction of the modern buildings in Cameroon are hollow concrete block, slab concrete or earth block [18]. In this work, typical composite wall structures shown in Fig. 2 are considered. From the exterior to the interior, the uninsulated wall consists of plaster $(2 \mathrm{~cm})$, hollow concrete block $(20 \mathrm{~cm})$ and plaster $(2 \mathrm{~cm})$ while the insulated wall consists of plaster $(2 \mathrm{~cm})$, insulation material (expanded polystyrene), hollow concrete block $(20 \mathrm{~cm})$ and plaster $(2 \mathrm{~cm})$. Thermal properties of plaster, hollow concrete block and expanded polystyrene used in the walls described in Fig. 2 are shown in Table 1.

\subsection{Optimization model of the insulation thickness}

The use of thermal insulation reduces the heat gain/loss through the building envelope, and thus, the energy consumption cost of the building. Nevertheless, the installation of the insulation layers in the external walls increases the initial cost of the building. Therefore, an economic analysis should be performed in order to estimate the optimum insulation thickness which minimizes the total cost [8].

The total cost $\left(C_{t}\right)$ is the sum of the cost of insulation material and the present worth of the cost of energy consumption over the lifetime of the building. It is given as:

$C_{t}=C_{e n r} P W F+C_{i n s} L_{i n s}$

where $C_{i n s}$ is the cost of insulation material per unit volume $\left(\$ \mathrm{~m}^{-3}\right), P W F$ is the present worth factor, $L_{i n s}$ is the insulation thickness and $C_{e n r}$ is the annual cost of energy consumption per unit wall area.

$C_{e n r}=\frac{Q_{c} C_{e l}}{C O P}$ 


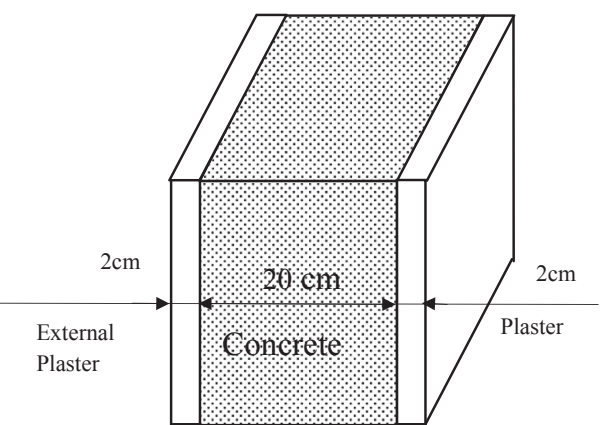

(a)

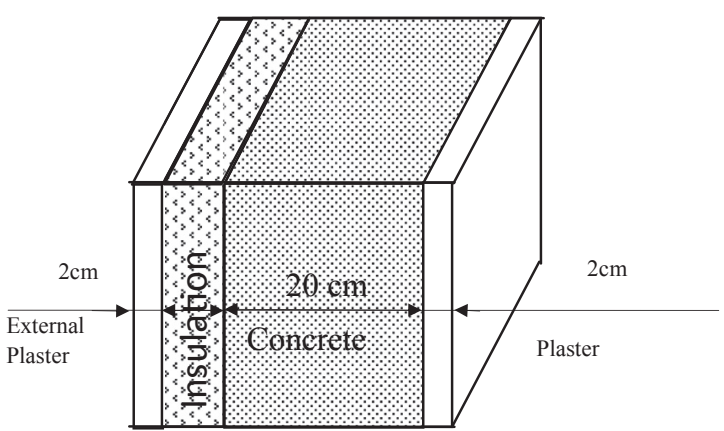

(b)

Fig. 2. Typical uninsulated (a) and insulated (b) wall structures.

Table 1

Material properties.

\begin{tabular}{lcc}
\hline Material & $\rho\left(\mathrm{kg} \mathrm{m}^{-3}\right)$ & $c\left(\mathrm{~J} \mathrm{~kg}^{-1} \mathrm{~K}^{-1}\right)$ \\
\hline Expanded polystyrene [19] & 10 & 1400 \\
Cement plaster [20] & 2200 & 1050 \\
Hollow concrete block [20] & 1250 & $\left.8.04 \mathrm{~m}^{-1} \mathrm{~K}^{-1}\right)$ \\
\hline
\end{tabular}

where $Q_{c}$ is the yearly cooling transmission need per unit area of external wall $\left(\mathrm{kWh} \mathrm{m}^{-2}\right), \mathrm{COP}$ is the coefficient of performance of air-conditioning system and $C_{e l}$ is the cost of electricity $\left(\$ \mathrm{kWh}^{-1}\right)$.

$P W F=\frac{(1+r)^{n}-1}{r(r+1)^{n}}$

where $n$ is the lifetime of the building and $r$ is a parameter depending on the inflation $(g)$ and the interest $(i)$ rates [21] given as:

$r=\frac{i-g}{1+g} \quad$ for $i>g$

$r=\frac{g-i}{1+i} \quad$ for $i<g$

For $i=g$, PWF $=\frac{n}{1+i}$

The energy savings is the difference between the total cost without insulation and the total cost with optimum insulation. The payback period $\left(p_{b}\right)$ can be obtained by solving the following equation:

$\frac{C_{i n s} L_{o p}}{A_{S}}=\operatorname{PWF}\left(p_{b}\right)$

where $A_{S}$ is the annual energy savings obtained by dividing the energy savings by the PWF. The parameters used in this section are

Table 2

Parameters used for calculations.

\begin{tabular}{ll}
\hline Parameters & Values \\
\hline Electricity for cooling & \\
Cost & $0.16 \$ / \mathrm{kWh}$ \\
COP & 2,5 \\
Expanded polystyrene & \\
Cost & $164.32 \$ / \mathrm{m}^{3}$ \\
Inflation rate, $g$ & $2.9 \%[22]$ \\
Interest rate, $i$ & $5 \%[23]$ \\
Life time, $n$ & 30 years \\
\hline
\end{tabular}

given in Table 2. The value of COP is the same as that used by Claessens et al. [20] when studying the efficiency of the active cooling methods in tropical region. The value of the lifetime used in this study is that found in literature $[8,9]$.

(a)

(b)
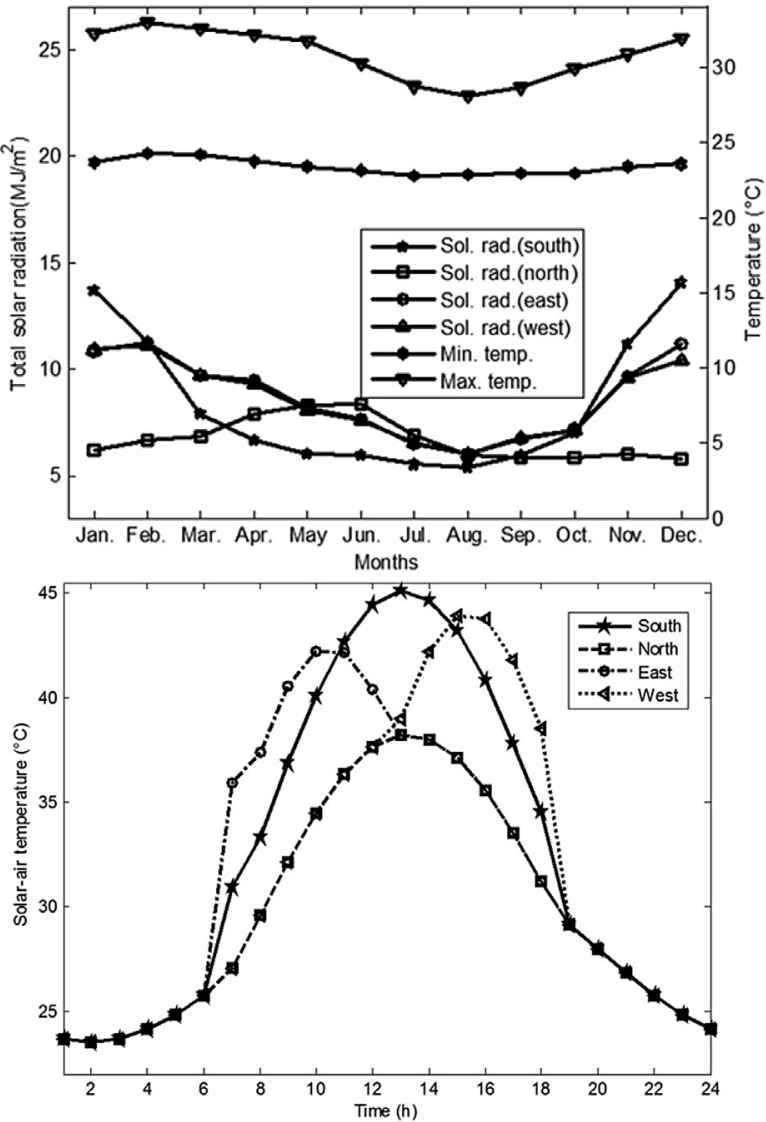

Fig. 3. Daily climatic variables for representative days of months (a) and hourly solarair temperature for December 15th. 


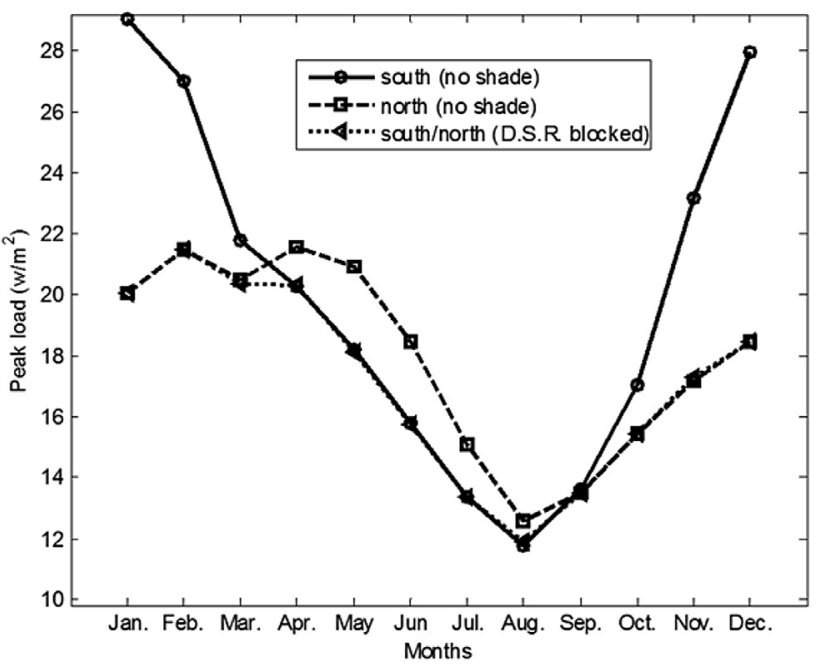

Fig. 4. Effect of intercepting direct solar radiation (D.S.R) reaching the wall on the peak cooling transmission loads for representative days of months.

\section{Results and discussion}

\subsection{Environmental conditions}

The study is carried out for a hollow concrete wall in the climatic conditions of Douala (latitude: $4^{\circ} 01^{\prime}$, longitude: $9^{\circ} 44^{\prime}$ and standard meridian: $15^{\circ} \mathrm{E}$ ). The outdoor temperature and solar radiation are assumed to be the average diurnal for each month (see Appendix). The indoor air temperature is kept constant at $T_{i}=24.50^{\circ} \mathrm{C}$ which is in the thermal comfort temperature range [24]. The solar absorptivity of considered wall is supposed to be equal to 0.6 (for medium color [16]). The exterior and the interior combined convection and radiation heat transfer coefficients ( $h_{0}$ and $h_{i}$, respectively) are selected to be 9 and $22 \mathrm{Wm}^{-2} \mathrm{~K}^{-1}$, respectively [8]. The daily climatic variables (total solar radiation on vertical surfaces and maximum and minimum temperatures) for representative days of months (assumed to be 15th) are presented in Fig. 3a. It is seen that the highest value of the monthly mean maximum air temperature that occurred in February is $33.05{ }^{\circ} \mathrm{C}$ while its lowest value that occurred in July is $22.81{ }^{\circ} \mathrm{C}$. It is also noted that the total daily radiation on a tilted surface depends on the day and wall orientation. The daily total solar radiation received by the vertical wall is highest $\left(14.08 \mathrm{MJ} \mathrm{m}^{-2}\right)$ for the south oriented wall in December and lowest $\left(5.40 \mathrm{MJ} \mathrm{m}^{-2}\right.$ ) for the same wall orientation in August. Thus, the solar radiation and temperature levels suggest where it should be beneficial to provide shade throughout the year. The hourly variations of solar-air temperature for all wall orientation on December 15 are plotted in Fig. 3b. The graph shows that the peak of hourly solar-air temperature $\left(45.09^{\circ} \mathrm{C}\right)$ obtained for wall facing south occurred approximately at $13 \mathrm{~h}$. The maximum value of solarair temperature of wall facing west is higher compare to that of east wall since the maximum outdoor temperature occurs at $14 \mathrm{~h}$ when the west oriented wall receives more solar radiation than east oriented wall. The last result is in harmony with that obtained by Ozel [10].

\subsection{Effect of shading on peak cooling transmission load}

In this section, the effect of shading is limited to the obstruction of the direct component of solar radiation only. The investigation is carried out for north and south facing walls. Fig. 4 presents the impact of intercepting direct solar radiation reaching the uninsulated wall on the peak cooling transmission load on the representative days of months. It is shown that obstructing the direct sunlight reaching the wall can provide reduction in peak cooling load up to $33.98 \%$ and $14.68 \%$ for south and north wall orientation, respectively. It is also noted that the highest reduction is obtained on the representative day of December (near winter solstice) for wall facing south and June for wall facing north (near summer solstice), respectively. It is also observed that the highest peak cooling load occurs in January for the unshaded wall facing south and its protection against direct solar radiation provide reduction in peak cooling load by $30.93 \%$.

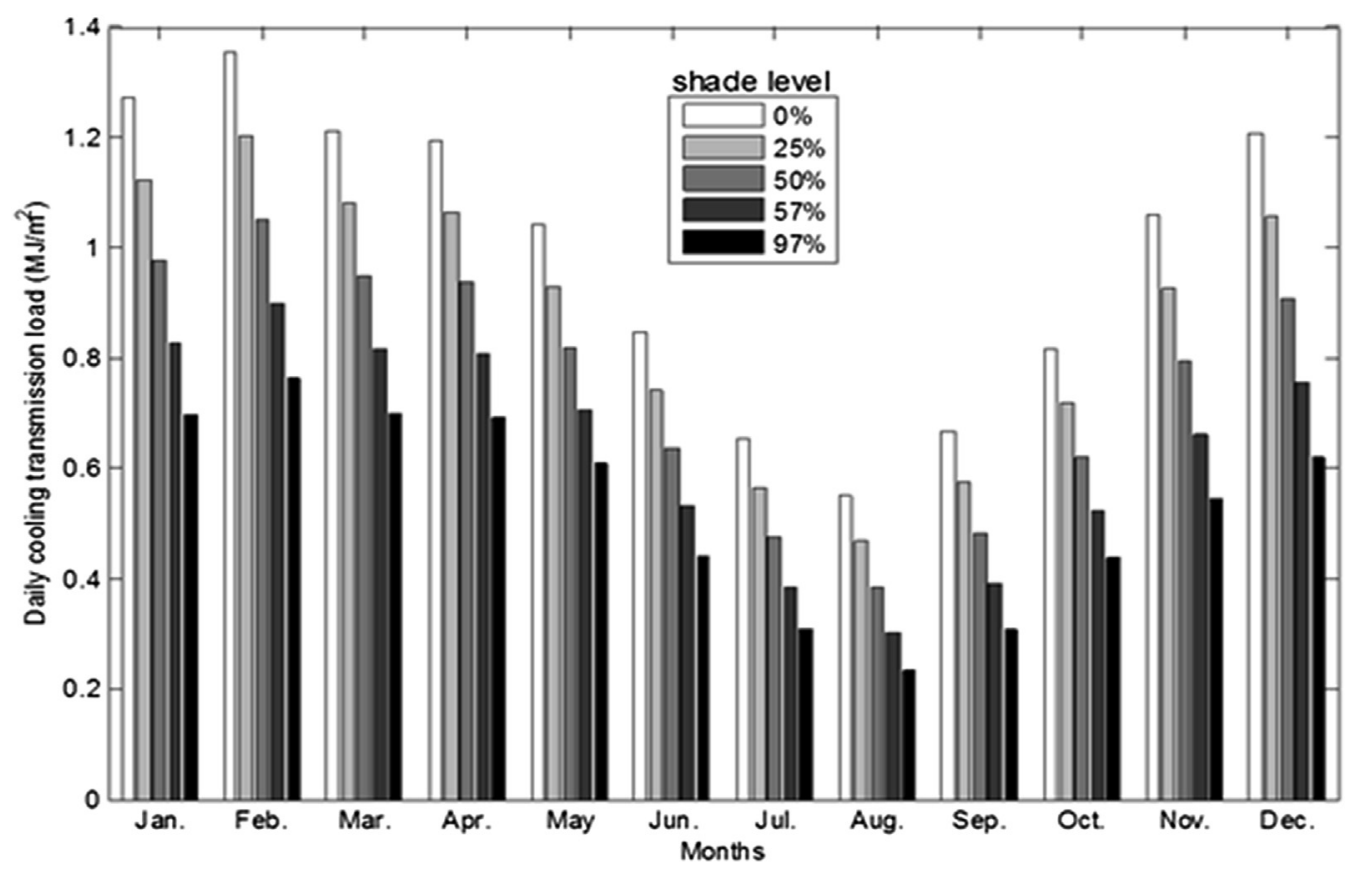

Fig. 5. Daily total cooling transmission load of uninsulated wall for the 15 th of each month according to shade level. 
(a)

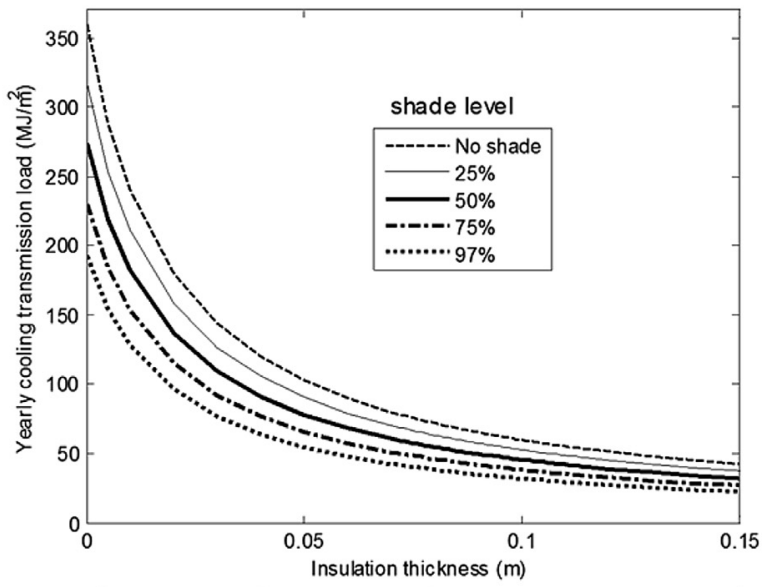

(b)

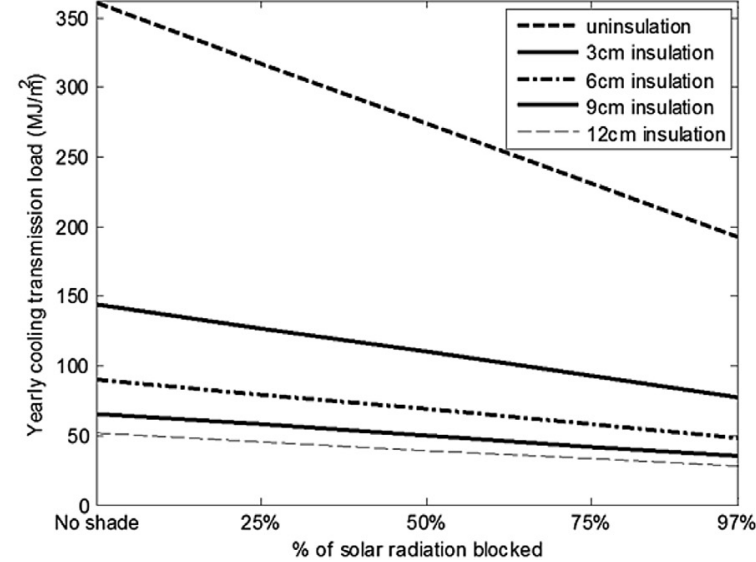

Fig. 6. Variation of annual cooling transmission loads versus insulation thickness with respect to shade level (a) and versus percentage of solar radiation blocked with respect to insulation level (b).

\subsection{Effect of shading on daily and yearly transmission loads}

The daily cooling transmission load on the representative day of each month for uninsulated wall with respect to shade level is plotted in Fig. 5. The results are shown for the east/west facing wall. It is seen that the highest value of daily cooling load occurred in February while its lowest value occurred in August. The results also show that as the percentage of solar radiation obstructed increases, daily cooling load decreases significantly for all days. It can be also noted that even at $97 \%$ shade, the daily heating load is zero for each

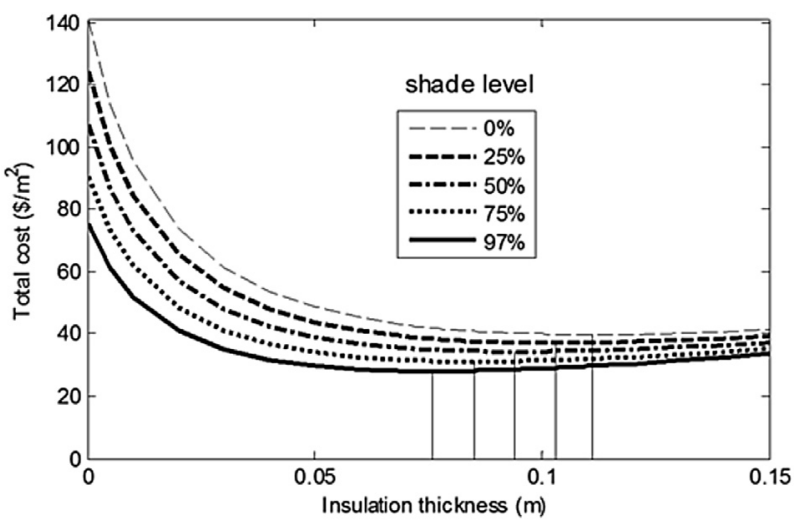

Fig. 7. Variation of total cost versus insulation thickness for east/west facing wall with respect to shade level.
Table 3

Optimum insulation thicknesses and its decrease rates with respect to shade level.

\begin{tabular}{|c|c|c|c|c|c|c|}
\hline \multirow[t]{2}{*}{ Shade levels (\%) } & \multicolumn{3}{|c|}{$\begin{array}{l}\text { Optimum insulation } \\
\text { thickness }(\mathrm{cm})\end{array}$} & \multicolumn{3}{|c|}{$\begin{array}{l}\text { Decrease rate }(\mathrm{cm} \text { per } \\
\text { percentage of solar } \\
\text { radiation blocked) }\end{array}$} \\
\hline & South & North & East/west & South & North & East/west \\
\hline 0 & 11.0 & 10.4 & 11.1 & & & \\
\hline 25 & 10.2 & 09.7 & 10.3 & 0.032 & 0.028 & 0.032 \\
\hline 50 & 09.4 & 09.0 & 09.4 & 0.032 & 0.028 & 0.036 \\
\hline 75 & 08.5 & 08.3 & 08.5 & 0.036 & 0.028 & 0.036 \\
\hline 97 & 07.6 & 07.6 & 07.6 & 0.040 & 0.032 & 0.041 \\
\hline Averages & & & & 0.035 & 0.029 & 0.036 \\
\hline
\end{tabular}

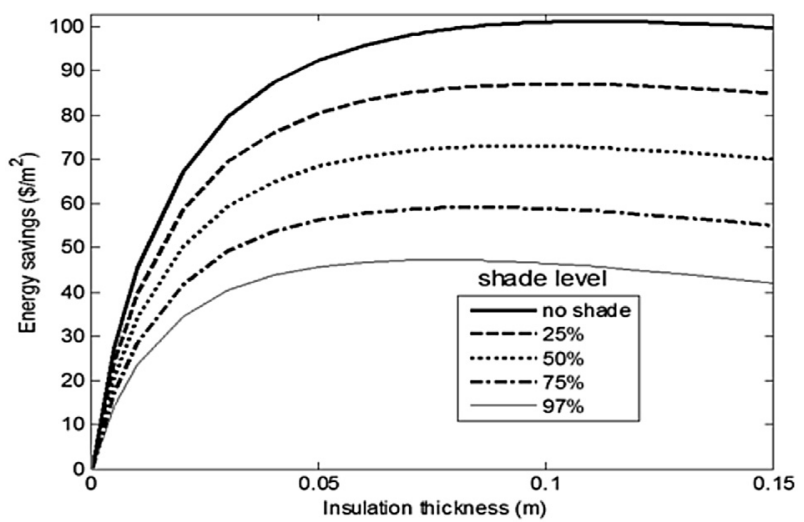

Fig. 8. Variation of energy savings versus insulation thickness with respect to shade level.

month. This is due to the fact that the ambient temperature level over the year is sufficiently high so that even in the absence of solar radiation, the zone does not require heating.

Fig. 6a presents the variation of yearly cooling transmission load versus insulation thickness with respect to shade level for the east/ west oriented wall. It is seen that yearly cooling load decreases with increasing insulation thickness. The last result is similar to those obtained in literature [10]. Fig. 6b depicts the variation of yearly cooling transmission load versus shade level with respect to insulation level. It is clearly seen that yearly cooling transmission load decreases linearly with shade level for all insulation thicknesses. The decrease rates are $1.73,0.69,0.43,0.31$ and $0.25 \mathrm{MJ} \mathrm{m}^{-2}$ per percentage of solar radiation blocked for uninsulation, 3, 6, 9 and $12 \mathrm{~cm}$ insulation wall, respectively. According to the last result, it can be noted that the effect of solar shading on the yearly cooling transmission load significantly decreases when increasing the insulation thickness.

\subsection{Effect of shading on optimum insulation thickness}

The effect of shading on the optimum insulation thickness is investigated in this study. The optimum insulation thickness is the thickness of insulation layer that provide the lowest total cost

Table 4

Energy savings with respect to shade level.

\begin{tabular}{lllc}
\hline Shade levels $(\%)$ & \multicolumn{2}{l}{ Energy savings $\left(\$ \mathrm{~m}^{-2}\right)$} \\
\cline { 2 - 4 } & South & North & East/west \\
\hline 0 & 99.37 & 88.38 & 101.29 \\
25 & 85.61 & 77.47 & 87.08 \\
50 & 72.04 & 66.68 & 73.04 \\
75 & 58.69 & 56.05 & 59.18 \\
97 & 47.20 & 46.89 & 47.25 \\
\hline
\end{tabular}


Table 5

Optimum insulation thickness, energy savings, payback periods and yearly cooling load at optimum thickness according to shade level.

\begin{tabular}{|c|c|c|c|c|c|c|}
\hline \multirow[t]{2}{*}{ Shade levels (\%) } & \multicolumn{3}{|c|}{ Payback period (years) } & \multicolumn{3}{|c|}{ Yearly cooling load at optimum thickness $\left(\mathrm{MJ} \mathrm{m}^{-2}\right)$} \\
\hline & South & North & East/west & South & North & East/west \\
\hline 0 & 3.59 & 3.79 & 3.56 & 54.62 & 51.88 & 55.08 \\
\hline 25 & 3.82 & 4.00 & 3.80 & 51.35 & 49.26 & 51.66 \\
\hline 50 & 4.14 & 4.26 & 4.09 & 47.61 & 46.31 & 48.16 \\
\hline 75 & 4.53 & 4.61 & 4.49 & 43.73 & 42.96 & 44.03 \\
\hline 97 & 4.95 & 4.97 & 4.94 & 40.16 & 39.95 & 40.20 \\
\hline
\end{tabular}

which is the sum of energy and insulation material cost. The acquisition cost of surrounding structures that protect walls from solar radiation is not taking into account.

Fig. 7 shows the variation of the total cost versus the insulation thickness for the east/west wall orientation with respect to shade level. It is seen that the total cost decreases with increasing the shade level for all insulation thicknesses. This is due to the fact that the energy cost which is proportional to the yearly cooling transmission load decreases with increasing the shade level.

Table 3 shows the optimum insulation thickness for various shade levels. For $s d=0$ ( $0 \%$ shade), the highest value of optimum insulation thickness is obtained for east/west facing wall $(0.111 \mathrm{~m})$ while its lowest value is obtained for north facing wall $(0.104 \mathrm{~m})$. The last result is similar to those obtained in the literature [14]. It is also seen that as shade level increases the optimum insulation decreases at the average rate of $0.035,0.029$ and $0.036 \mathrm{~cm}$ per percentage of solar radiation blocked for south, north and east/west oriented wall, respectively. One can note that the impact of solar shading on optimum insulation thickness is more significant for the east/west facing wall. It can be also noted that the value of optimum insulation thickness is the same $(0.076 \mathrm{~m})$ for all wall orientations for $s d=97$. This is due to the fact that the influence of the solar radiation on the cooling transmission load becomes insignificant at $97 \%$ shade.

The variations of energy savings versus insulation thickness with respect to shade level are shown in Fig. 8 for the east/west wall orientation. It can be seen that energy savings decreases when increasing the shade level for all insulation thicknesses. The highest value of energy savings is obtained for the optimum insulation thickness at all shade levels. Table 4 presents the energy savings for all wall orientations and for various levels of shade when the optimum insulation thickness is used. It is seen that as shade level increases, energy savings decreases for all degrees of shade. At any shade level, the highest value of energy savings is obtained for east/ west oriented wall while its lowest value is obtained for north oriented wall.

The payback period and yearly cooling transmission load when optimum insulation thickness is used for all wall orientations and for different levels of shade are summarized in Table 5. The results show that yearly cooling load decreases while payback period increases with increasing shade level. The highest value of payback period is obtained for north oriented wall while its lowest value is obtained for east/west facing wall for all levels of shade. It is also noted that as shade level increases from 0 to $97 \%$, yearly cooling load decreases by $22.99 \%, 26.47 \%$ and $27.02 \%$ for north, south and east/west oriented walls, respectively.

\section{Conclusion}

The main purpose of this work was to optimize the thicknesses of insulation layers in external walls of continuously used building in a tropical region with respect to shade level. A Simulink model was constructed from the H-Tools library to estimate the instantaneous heat flux on the inside surface of a typical composite wall while its external surface is exposed to the climatic conditions of Douala in Cameroon. The effect of shading on the peak cooling transmission load was investigated. Results show that intercepting direct component of solar radiation reaching the wall can provide reduction in peak cooling load up to $34 \%$.

The instantaneous heat flux on the inside surface of the considered wall was integrated to determine the daily and yearly transmission loads with respect to shade level. Results showed that solar shading has significant effect on the cooling transmission load. It was also seen that even at $97 \%$ shade, heating transmission load is zero for the uninsulated or insulated wall.

The yearly cooling load with respect to shade level was used as input in an economical model to estimate the optimum insulation thicknesses, energy savings and payback periods. Results showed that as the level of shade increases, optimum insulation thickness and energy savings significantly decrease while payback period significantly increases. The optimum insulation thickness decreases at the average rate of $0.035,0.029$, and $0.036 \mathrm{~cm}$ per percentage of solar radiation blocked for south, north and east/west oriented walls, respectively. It was also seen that the impact of external shading on optimum insulation thickness is more significant for east/west facing wall.

Considering the consistent impact of shade level on optimum insulation thickness, the design of external walls thermal insulation in a tropical region should take into consideration the shade level of the building site. The procedure proposed in this work should allow others investigations where different economic parameters and climatic conditions can be considered.

\section{Acknowledgements}

The authors would like to acknowledge the Department of National Meteorology of Cameroon for providing the long-term dry bulk air temperature data.

\section{Appendix A}

\section{A.1. Hourly generation of air temperature}

Average hourly air temperature $\left(T_{0}\right)$ for a representative day of each month is estimated by interpolating a long-term (1985-2005) averaged values of monthly mean maximum $\left(T_{\max }\right)$ and minimum ambient $\left(T_{\min }\right)$ temperatures provide by the Department of $\mathrm{Na}$ tional Meteorology of Cameroon using the cosine model [25] expressed as:

$T_{0}=\frac{T_{\max }-T_{\min }}{2} \cos \left(\frac{\pi(t-a)}{12}\right)+\frac{T_{\max }+T_{\min }}{2}$

where $a$ is the time of the occurrence of maximum temperature taking as 14 in this study [25]. $T_{0}$ is in the range of $1-24 \mathrm{~h}$. 


\section{A.2. Estimation of hourly values for solar radiation}

The monthly averages of daily global and diffuse solar radiation on horizontal surface are calculated using a long-term (1985-2004) averaged values of monthly data supplied by Helioclim1 [26]. Then, the correlation proposed by Collares-Pereira and Rabl [27] and expressed below is used to estimate the monthly average hourly global radiation ( $I$ ) from the monthly average of daily global radiation $(H)$.

$\frac{I}{H}=(a+b \sin \omega) \frac{\pi}{24} \frac{\cos \omega-\cos \omega_{s}}{\sin \omega_{s}-\left(\frac{\pi \omega_{s}}{180}\right) \cos \omega_{s}}$

where

$a=0.409+0.5016 \sin \left(\omega_{s}-60^{\circ}\right)$

$b=0.6609-0.4767 \sin \left(\omega_{s}-60^{\circ}\right)$

where $\omega_{s}$ is the sunset hour angle.

According to Liu and Jordan [28] $I_{d} / H_{d}$ is equal to $I_{0} / H_{0}$ and can be expressed as:

$\frac{I_{d}}{H_{d}}=\frac{I_{0}}{H_{0}}=\frac{\pi}{24} \frac{\cos \omega-\cos \omega_{s}}{\sin \omega_{s}-\frac{\pi \omega_{s}}{180} \cos \omega_{s}}$

The above correlation is used to estimate the monthly average of hourly diffuse radiation on horizontal surface $\left(I_{d}\right)$. The hourly direct radiation $\left(I_{b}\right)$ is obtained by subtracting the hourly diffuse radiation from the hourly global radiation.

\section{Nomenclature}

$A_{s} \quad$ annual energy savings $\left(\$ \mathrm{~m}^{-2}\right)$

$c \quad$ specific heat $\left(\mathrm{J} \mathrm{kg}^{-1} \mathrm{~K}^{-1}\right)$

C $\quad \operatorname{cost}(\$)$

COP coefficient of performance of air-conditioning system

$g \quad$ inflation rate (\%)

$h \quad$ combined heat transfer coefficient $\left(\mathrm{W} \mathrm{m}^{-2} \mathrm{~K}^{-1}\right)$

$H$ monthly average of daily global radiation on horizontal surface $\left(\mathrm{MJ} \mathrm{m}^{-2}\right.$ day $^{-1}$ )

$H_{0} \quad$ monthly average of daily extraterrestrial radiation on horizontal surface $\left(\mathrm{MJ} \mathrm{m}^{-2}\right.$ day $^{-1}$ )

$H_{d} \quad$ monthly average of daily diffuse radiation on horizontal surface (MJ m${ }^{-2}$ day $^{-1}$ )

$L \quad$ wall thickness ( $\mathrm{m}$ )

$L_{o p} \quad$ optimum insulation thickness (m)

$i \quad$ interest rate (\%), order of node

I total solar radiations on the horizontal surface $\left(\mathrm{W} \mathrm{m}^{-2}\right)$

$I_{b} \quad$ direct solar radiations on the horizontal surface $\left(\mathrm{W} \mathrm{m}^{-2}\right)$

$I_{d} \quad$ diffuse solar radiations on the horizontal surface $\left(\mathrm{W} \mathrm{m}^{-2}\right)$

$I_{0} \quad$ hourly extraterrestrial radiation $\left(\mathrm{W} \mathrm{m}^{-2}\right)$

$N \quad$ number of nodes

$n \quad$ lifetime of building (years)

M number of layers of composite wall

$p_{b} \quad$ payback period (years)

$q_{i} \quad$ heat flux density at indoor surface of the wall $\left(\mathrm{W} \mathrm{m}^{-2}\right)$

$Q_{c} \quad$ annual cooling transmission load $\left(\mathrm{MJ} \mathrm{m}^{-2}\right)$

sd shade level

$t$ time (s)

$T$ temperature $\left({ }^{\circ} \mathrm{C}\right)$

$x \quad$ coordinate direction normal to wall (m)

\section{Greek symbols}

$\alpha \quad$ solar absorptivity of outside surface of wall

$\gamma \quad$ surface azimuth angle $\left(^{\circ}\right)$ $\delta \quad$ declination angle $\left(^{\circ}\right)$

$\lambda \quad$ thermal conductivity $\left(\mathrm{Wm}^{-1} \mathrm{~K}^{-1}\right)$

$\phi \quad$ latitude $\left({ }^{\circ}\right)$

$\omega \quad$ hour angle $\left({ }^{\circ}\right)$

$\omega_{s} \quad$ sunset-hour angle for a horizontal surface $\left(^{\circ}\right)$

$\rho \quad$ density of material $\left(\mathrm{kg} \mathrm{m}^{-3}\right)$

$\rho_{r} \quad$ ground reflectivity

$\begin{array}{ll}\text { Subscripts } \\ \text { el } & \text { electricity } \\ \text { enr } & \text { energy } \\ i & \text { inside } \\ \text { ins } & \text { insulation } \\ \text { max } & \text { maximum value } \\ \text { min } & \text { minimum value } \\ o & \text { outside } \\ \text { sa } & \text { solar-air } \\ t & \text { total }\end{array}$

\section{References}

[1] G. Papadakis, P. Tsamis, S. Kyritsis, An experimental investigation of the effect of shading with plants for solar control of buildings, Energy Build. 33 (2001) $831-836$.

[2] A.L.S. Chan, Effect of adjacent shading on the thermal performance of residential buildings in a subtropical region, Appl. Energy 92 (2012) $516-522$.

[3] S. Nikoofard, V.I. Ugursal, I. Beausoleil-Morrison, Effect of external shading on household energy requirement for heating and cooling in Canada, Energy Build. 43 (2011) 1627-1635.

[4] A. Ucar, F. Balo, Determination of the energy savings and the optimum insulation thickness in the four different insulated exterior walls, Renew. Energy 35 (2010) 88-94.

[5] B.B. Ekici, A.A. Gulten, U.T. Aksoy, A study on the optimum insulation thicknesses of various types of external walls with respect to different materials, fuels and climate zones in Turkey, Appl. Energy 92 (2012) 211-217.

[6] J. Yu, C. Yang, L. Tian, D. Liao, A study on optimum insulation thicknesses of external walls in hot summer and cold winter zone of China, Appl. Energy 86 (2009) 2520-2529.

[7] N. Daouas, Z. Hassen, B.H. Aissia, Analytical periodic solution for the study of thermal performance and optimum insulation thickness of building walls in Tunisia, Appl. Therm. Eng. 30 (2010) 319-326.

[8] N. Daouas, A study on optimum insulation thickness in walls and energy savings in Tunisian buildings based on analytical calculation of cooling and heating transmission loads, Appl. Energy 88 (2011) 156-164.

[9] S.A. Al-Sanea, M.F. Zedan, Improving thermal performance of building walls by optimizing insulation layer distribution and thickness for same thermal mass, Appl. Energy 88 (2011) 3113-3124.

[10] M. Ozel, Determination of optimum insulation thickness based on cooling transmission load for building walls in a hot climate, Energy Convers. Manage. 66 (2013) 106-114.

[11] M. Woloszyn, C. Rode, Tools for performance simulation of heat, air and moisture conditions of whole buildings, Build. Simul. 1 (2008) 5-24.

[12] F. Collet, L. Serres, J. Miriel, M. Bart, Study of thermal behaviour of clay wall facing south, Build. Environ. 41 (2006) 307-315.

[13] Ibpt library. IBPT-1. <http://www.ibpt.org/libraries.html>, [accessed 12.05.14].

[14] M. Ozel, Effect of wall orientation on the optimum insulation thickness by using a dynamic method, Appl. Energy 88 (7) (2011) 2429-2435.

[15] M. Ozel, The influence of exterior surface solar absorptivity on thermal characteristics and optimum insulation thickness, Renew. Energy 39 (2012) $347-355$.

[16] H. Suehrcke, E.L. Peterson, N. Selby, Effect of roof solar reflectance on the building heat gain in a hot climate, Energy Build. 40 (2008) 2224-2235.

[17] T.R. Nielsen, R. Peuhkuri, P. Weitzman, C. Gudum, Modeling Building Physics in Simulink, Report SR-02-03, BYG DTU, 2002.

[18] A. Kemajou, L. Mba, Matériaux de construction et confort thermique en zone chaude application au cas des régions climatiques camerounaises, Rev. Des. Energies Renouvelables 14 (2011) 239-248.

[19] A.S. Kalagasidis. Common Exercise 1. Modelling Details and Results. Annex 41 publication CTH Oct 2004 Paper A41-T1-S-04-3. <http://www.kuleuven.be/ bwf/projects/annex41/protected/data/CTH\%200ct\%202004\%20Paper\%20A41T1-S-043.pdf $>$, [accessed 12.05.14].

[20] J. Claessens, Y. Coulibaly, A. Kemajou, Efficacité énergétique de la climatisation en région tropicale. <www.ifdd.francophonie.org/docs/prisme/eeTOME1.PDF $>$, [accessed 20.09.14] 
[21] M. Arıcı, H. Karabay, Determination of optimum thickness of double-glazed windows for the climatic regions of Turkey, Energy Build. 42 (2010) $1773-1778$.

[22] Inflation, consumer prices (annual \%). <http://data.worldbank.org/indicator/ FP.CPI.TOTL.ZG>, [accessed 29.08.14].

[23] Prêt Foncier Epargne Logement Ordinaire. <http://www.creditfoncier.cm/ index.php/fr/pret-foncier-epargne-logement/pret-foncier-epargne-logementordinaire $>$, [accessed 29.08.14].

[24] M.S. Al-Homoud, A.A. Abdou, I.M. Budaiwi, Assessment of monitored energy use and thermal comfort conditions in mosques in hot-humid climates, Energy Build. 41 (6) (2009) 607-614, http://dx.doi.org/10.1016/ j.enbuild.2008.12.005.
[25] C.T. De Wit, Simulation of Assimilation, Respiration and Transpiration of Crops, Pudoc, Wageningen, 1978, p. 148.

[26] HelioClim1, Daily irradiance averaged over the Month, over the horizontal plane. <http://www.soda-is.com/eng/services/service_invoke/gui.php?xmlde script=hc1month.xml\&Submit=HC1 month $>$, [accessed 17.08.14].

[27] M. Collares-Pereira, A. Rabl, The average distribution of solar radiation correlation between diffuse and hemispherical and between daily and hourly insolation values, Sol. Energy 22 (1979) 155-164.

[28] B.Y.H. Liu, R.C. Jordan, Daily insolation on surfaces tilted toward the equator, ASHRAE J. 3 (10) (1962) 53-58. 